\title{
Functional Dimensions at 'Kuala Lumpur Waterfront'
}

\author{
Nurul Syala Abdul Latip¹, Shuhana Shamsudin², Mohd Shahir Liew³ \\ 1 Faculty of Built Environment, University of Nottingham, Nottingham \\ 2 Univcrsiti Technology. Malaysia City Campus, Kuala Lumpur, Malaysia, \\ 3 Petronas University of Technology, Malaysia \\ syala09@gmail.com
}

\begin{abstract}
The 'Kuala Lumpur Waterfront' may be unfamiliar to many. Kuala Lumpur is a city that originates at the confluence of two rivers, the Klang and Gombak Rivers. The waterfront used to be very busy with activities when it was once a trading post for the export of tin. This was once the lifeline of the city - its main mode of transportation. The activity at the waterfront has changed over the years along with the social, economic and physical development of the city. Many waterfront cities throughout the world have gone through similar changes when the mode of transportation changed from water to the motor system. A number of cities have made efforts to integrate the cities' activities with their water body. This research attempts to investigate the functional aspects at the Kuala Lumpur waterfront within the city centre in terms of its level of contextual integration with the urban rivers in the current context. The technique adopted for this research is field observations which include building use survey and time interval observation to investigate the Junctional aspects in ten demarcated zones along the Kuala Lumpur waterfront within the city centre. The research concluded with the finding that all the zones have medium level of contextual integration between the waterfront and the urban river in terms of its building use, which depends much on the continuity of activities, their positioning location, accessibility and the provision of space and facilities.
\end{abstract}

Keywords: Contextual integration, waterfront, urban river, activity

ISSN 2514-751X @ 2016 The Authors. Published for AMER ABRA by e-International Publishing House, Ltd., UK.. This is an open access article under the CC BY-NC-ND license (http://creativecommons.org/licenses/by-nc-nd/4.0/). Peerreview under responsibility of AMER (Association of Malaysian Environment-Behaviour Researchers), ABRA (Association of Behavioural Researchers on Asians) and cE-Bs (Centre for Environment-Behaviour Studies), Faculty of Architecture, Planning \& Surveying, UniversitiTeknologi MARA, Malaysia.

https://doi.org/10.21834/aje-bs.v1i1.164 


\subsection{Introduction}

A lot of effort towards waterfront reintegration is taking place all over the world with the aim of achieving sustainable development. It has become the consideration of many cities that, in order to create a better public realm at the waterfront areas, urban design with contextual integration is used as one of its main tools (Hoyle, 2(01). The definition of contextual integration in this research is the physical and functional relationship between a development and its surrounding (Carmona, 2000). In this case, it is the water body itself. A positive contextual integration with its water body will allow the public to enjoy the existence of water body in their city. This paper focuses on the evaluation of the functional aspect in terms of its level of contextual integration between the waterfront and the urban river.

\subsection{Literature Review}

In the search for an appropriate dimension to evaluate the functional aspects in terms of the level of contextual integration between the waterfront and the urban river, integrative theory of urban design by Sternberg (2000) was found to be highly related to this study. He categorized vitality as an important principle related to the functional aspect. The theory explained the relationship between developments with its surrounding which promotes integration across property lines. That is significantly related to this research which seeks to evaluate the contextual integration between the waterfront and the urban river situated across its property boundary. This principle is advocated by Jacobs (1961) who criticised the planning of the midcentury which neglected the importance of the diversity of urban life through their creation of dead vacant zones, 'clearing' the city through the urban 'renewal' programme and planning separate uses through the concept of zoning. Jacobs opined that the bustling street life is important in good cities and the closer grain on the density of uses will allow them to support each other better. In achieving balance, cities should not only have the bustling street with mix use activities but at the same time have the provision of quieter streets for residential area. Through vitality, her ideas promote integration across the property lines and relate well to the integrative theory (Sternberg, 2(00). This was also accorded by Browser (from Nasar, 1998) who highlighted that people do not really want to see sameness in all parts of the city. In reference to this principle, drawn from the literatures related to waterfront developments, two main dimensions were identified vital in the evaluation of the functional aspects of the contextual integration in between the waterfront and the urban river: i) the diversity of use and activity in the area that can allow the user to stay longer at the water edge; ii) continuity of activity at the building along the waterfront.

\subsection{Diversity of use}

Most of the literature mentioned in the following discussion stressed the importance of functional diversity to allow the public to be reconnected to the river and this should not reduce the opportunity of the general public to enjoy the waterfront (Donald Wood, 1965). This is 
similar to streets. According to Schumacher (from Moughtin, 1992), the liveliness of the street depends much on the variety of activity and attraction it can offer and will make the user stay longer.

The same encouragement was given in the redevelopment of harbour communities in downtown America, where these activities were urged to be considered in the earlier part of the development before any other activity took place (Kotval and Mullin, 2001). Petrillo (1985) mentioned that having human activity could enhance the waterfront area and add to the natural setting. In enhancing it, it is better to consider the existing surrounding activity as in the case of California's coastal program which moved to ensure that the new construction of the urban waterfront would be compatible in the type of use with the existing surrounding to avoid introducing something that was out of place or not acceptable by the locals (users).

The integration on the diversity of use in both land and water is found significant to allow for 'more dynamic opening onto the water' and vibrant waterfront area (Mann, 1988). Some cities increase the waterfront attachment through commercial investment by having diversity of use through their public water transportation such as ferry services and water buses. Waterfront transportation is also very much related to recreational appeal through the viewing and visits of the working vessels, educational vessels and water taxis (Tunbridge, 1988). West (1989) stated that in North America, many of the renewal efforts were concentrated on waterfront enhancement activities such as up-scale restaurants, cafes, condominiums, hotels, and giftshops, all of which benefitted environmentally and economically compared to waterfront dependent activities. Waterfront dependent activities such as boating, marinas and others were considered low-profit operations and operated because it was perceived to be more related to the waterside activity.

Significant difference of waterfront usage was perceived in the context of the waterfront in Ujjain. The activities were very much dependent on the water for ritual and daily worship and the water was also used for daily chores such as washing and laundry. At the periphery of the area, many commercial activities enhanced the waterfront further. This mix of activities made the waterfront and its water body an inseparable entity (Samant, 2004). The study by Hoyle (1994) on 'Canadian Perceptions of Waterfront Development' towards the difference between waterfront development and other development in the inner city found that the respondents stressed the importance of recreational facilities and noted that it should be provided not only on land but with a 'careful blending of land and water use'. Balsas (2007) mentioned that a public place in a city could become lively if they maintain their sense of place and reinforce their uniqueness that originated from the diversity of uses. It is obvious from many of the examples across the literature that diversity of use to integrate the waterfront with the water body is vital.

\subsection{Continuity of activities along the waterfront.}

Trancik (1987) mentioned that it was important to have a continuity of the walls as the frontage of a public place to create an enclosure of space in providing a setting for activities to happen at the ground floor area. He further explained that the frontage character and the continuity of the 
wall was one of the most important factors in determining the public place's success or failure. Relating to the waterfront, and drawing from the literature, the suggested dimension could be in the context of the 'continuity of activities along water body at the waterfront area'. As mentioned by Petrillio (1985), it was the variety of activities in different 'shape, scale and locations' that made a journey meaningful and pleasurable. Owens (1993) opined that buildings which were spaced closely would be able to give the sidewalk or street a 'strong spatial enclosure'. This was especially so

if the buildings were of 'mixed used commercial area'. The buildings created an edge to the street rather than 'as a free standing object in a space'. However, if the buildings were spread apart from one to another, the definition of the street was weakened. Jacobs (1961) opined that having continuous activities along the streets would provide a natural surveillance and give a feeling of safety for the user.

Continuity of activities in the urban space could also be experience through dynamic and static space. McCluskey (1992) suggested that the urban environment comprised of 'system of places connected by routes'. The dynamic spaces were mostly linear in shape that could be related to 'route'. However, static space might be in the shape of a square or circle and could be related to 'place'. A clear example in the urban area could be seen in the terraced buildings which created 'route' and clustered layout building that formed a 'place'. The static space provided a 'sense of completeness and rest' and for the dynamic space it implicated the sense of 'change and movement'. He opined that a good townscape which had its major concern in creating a sense of place should be aimed at increasing the static and reducing the dynamic aspects of space.

Gehl (1986) argued that pedestrian activities varied according to the quality of the environment. There were three categories of activities highlighted which were 'necessary', 'optional' and 'social/resultant' activities. The necessary activities were those which would happen and not dependent on the environment. Examples of this type of activities are such as walking to work or to school that will not depend so much on the quality of the environment because they need to be done somehow. However, optional activities are those activities that exist as a result of the situation and highly sensitive to the surrounding environment such as sitting and strolling. This will more likely to happen if the environment is more inviting. The social or resultant activities are activities which happen when other people are around in the same area.

May (2006), in her discussion of 'Connectivity' in Urban Rivers' highlighted the importance of continuity of activities along the riverfront through the Buffalo Bayou Master Plan. The urban planners for the masterplan had emphasised the connection of the urban river to humans. This was done through connecting the social and cultural attraction along the river which connected both the waterfront and the urban river. Its aim was to create balance between the built environment and natural environment for the purpose of sustainability. They believed that having an attractive and lively urban river would reduce the need for the residents to travel outside the city for recreation and fresh air. This is also consistent with the opinion of the Project for Public Spaces Team (www.pps.org/waterfronts/) that has more than thirty years of 
experience in designing public places which include waterfront. They suggested the importance of having continuity of activity for pedestrians which included a wide variety of activities as one of the keys to have a positive integration between the waterfront and the water body. From the literature, it is apparent that continuous activities along the river are one of the key dimensions that may contribute to the integration between the waterfront and the urban river.

\subsection{Methodology}

\subsection{Data Collection}

In investigating the functional aspects at the waterfront, direct observation study was employed. The technique of study was being divided into two parts which were: i) the building survey to identify the building use and continuity of activities, ii) time interval samplings to record the activities that happened and the continuity of activities in the area in relation to the urban river, using the narrative methods (Brandt, 1972 from Friedmann et. al, 197X) and supported by photographic documentation (Davis and Ayers, 1975 from Sanoff, 1991). Areas of observation were chosen based on the availability of visual points that could see both the waterfront and the urban river without obstacle. To reduce errors in judgments, two observers were located in each zone (Friedmann, 1978) to note the activities and at the same time map the activities in its location as it happen within an interval of one hour. There were 15 demarcated zones. Zone 2 and the left bank of zone $4 \mathrm{~b}$ were excluded from this study due to safety reasons. Zone 5 and Zone 8 were excluded due to the existing highway which totally blocked the integration between the waterfront and the urban river

Ten zones within the fifty metre range from both sides of the riverbank $(010,2003)$ were involved in this research (Figure I). No categorization of activities was made on site. Types of activity were given labels for easy mapping. Photo documentation was done every hour at every zone. The days for observations were: Monday $(6: 30 \mathrm{am}-8 \mathrm{pm})$ as (representative of Tuesday to Thursday which were the normal working days); Friday (6:30am-8pm). There was a congregational prayer (compulsory for Muslim men) at noon time which might change the activity in the city centre during noon; Saturday $(6: 30 \mathrm{am}-8 \mathrm{pm})$. It was a half-day working for some people and it might have some difference in the activity; Sunday (6:30am8pm). A full nonworking day that might have some difference in the activity. Public holidays or any other festive seasons were not included due to the one-off situation (Norsidah Ujang, 2(08).

\subsection{Data Analysis}

The parameter for the analysis were adapted and modified based on Lynch (1976) and Wren (1983). Building use was categorised according to the high, medium and low (Lynch, 1976) based on the parameters in Figure 2. 


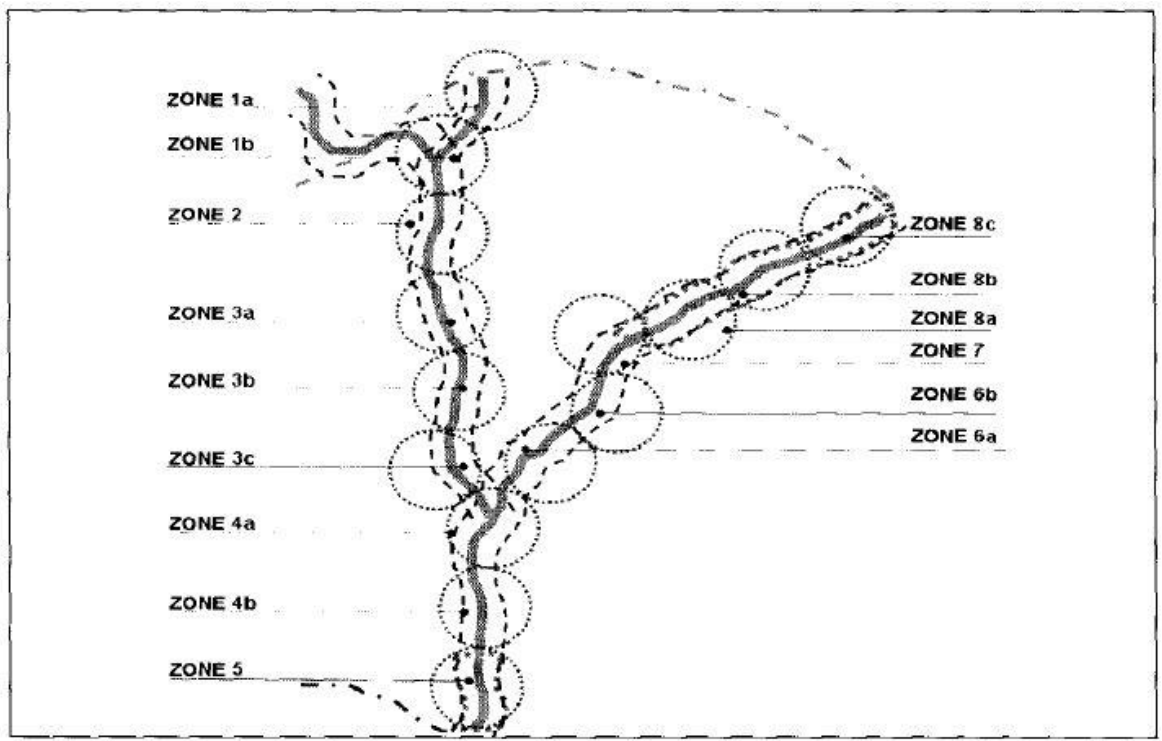

Figure 1: Map showing demarcated zones

\begin{tabular}{|c|c|}
\hline High & Water-dependent + water-related building use \\
\hline Medium & Water-related + water-independent building use \\
\hline Low & Independent building use \\
\hline
\end{tabular}

Figure 2: Parameters to evaluate the level of integration in the 'diversity of use' dimension in the demarcated zones. Adopted and modified from: Wren, 1983 and Lynch, 1976.

Water-dependent building uses are dependent on the availability of the urban river for the building to function. Without the urban river the building cannot function. Example of these types of building uses are marina, jetties and boathouses, and water-taxi stations. The second category is water-related uses. These are building use which has an advantage if it is close to the water hut can also function in other areas. Examples of these types of buildings/ development are restaurants, open spaces/parks/terraces, and resorts/hotels. Finally, waterindependent uses are those building that can function equally the same in other areas of the city without the water. Examples of these types of developments are shophouses/shopping complexes, offices, workshops, mosques, residential, schools and clinics. In order to evaluate the level of contextual integration in terms of the diversity of uses between the waterfront and the water body, it is very important for the area which has its own uniqueness to have a 'careful blending of land and water use' (Hoyle, 1994). Therefore, the 'diversity of uses' that may contribute to a high level of contextual integration refers to areas which offer a mix of land and 
water uses (a mix of water-dependent and water-related building use). It may contribute to a medium level of contextual integration if it offers a mix of only land base uses with some buildings still relate to the water body (a mix of water-related and water independent building use). Finally, it may contribute to a low level of contextual integration if an area only offers building uses which is not related to the water body (independent building use).

\begin{tabular}{|c|c|}
\hline High & Static activity \\
\hline Medium & Dynamic activity \\
\hline Low & No activity \\
\hline
\end{tabular}

Figure 3: Parameter used to evaluate level of integration in the continuity of activities in the demarcated zones.

(Adopted and modified from: McCluskey, 1992 and Lynch, 1976)

As for the user activity identified through the time interval observation and mapping sampling, each and every activity found was later categorised into live related groups of leisure, commercial, transportation, administration and maintenance, and others according to the time and days in table format. Each of the activities occurred was given a numerical figure (1) according to the hour it happened in order to calculate the frequency the activity occurred. Bar charts were produced from the results for easy understanding of the type and pattern of activity throughout the days at every zone. The scale used by Lynch (1976) was used to determine the level of contextual integration in terms of the continuity of activities between the waterfront and the urban river. It might be high if the area allowed static activity to happen i.e., it allowed the public to stay longer and enjoy the urban river. It was evaluated as medium if it offered only dynamic activities to happen which enhanced the area but not allowing for people to stay longer. It was deemed low if there was no activity generated in the area (Figure 3).

\subsection{Results and Discussions}

According to Jacobs (1961), the diversity of use and continuity of activities are important to sustain the vitality of a city. Through the use of scoring technique (Figure 3 ), it is suggested that all demarcated zones studied are in the medium level of integration with the urban river (Table I). This is because in all areas there is a mix of both water-related and waterindependent building use only. And none of the area has only the water-independent building use which may contribute to a total low level of integration and none of the area has the water-dependent building use which may contribute to the high level of integration between the waterfront and the urban river. Therefore, the functional aspects (building use and activity) are further investigated in terms of its continuity of activities which may contribute to the vitality in all zones. This is important to establish why and how these aspects are contributing to the level of integration between the waterfront and the urban river 


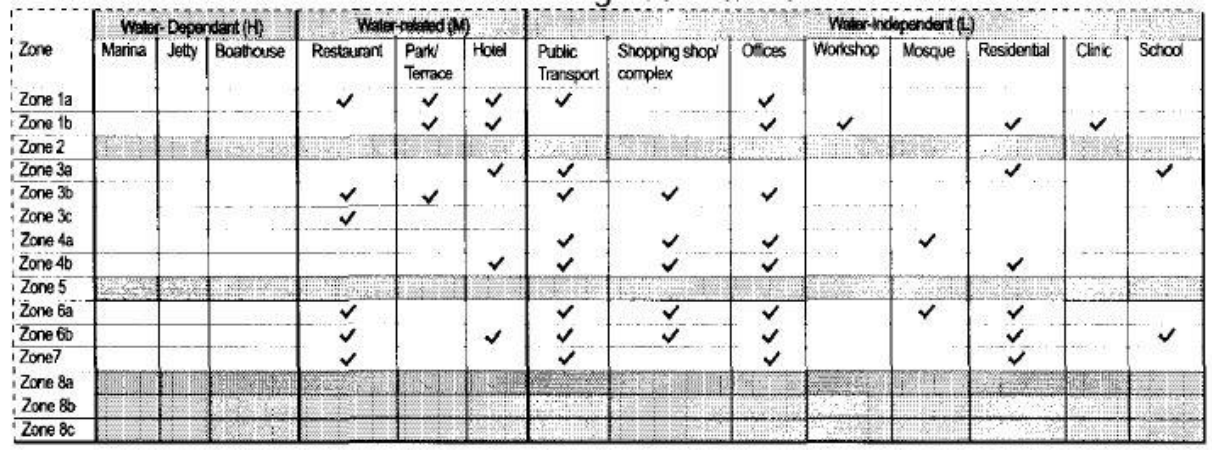

Table 1: Building use in all zones

\subsection{Water-related building use}

Based on the observation done, though the type of water-related use existed in most of the zones (Table I), there were other factors suggested to be vital in instigating the contextual integration between the waterfront and the urban river. This situation could be seen in zone $6 \mathrm{a}$, the three restaurants that opened 24hours, did not depend or directly related with the urban river, but allowed people to connect to the river visually and enhanced the riverfront. It invited people to hang out in the area till late night and created an overspill of optional/static activity at the pedestrian walkway along the waterfront. Though other zones (La, 3b, 3c, 4a, 6a, 6b, 7) did have restaurant in their areas, the positioning of the restaurant played an important factor in determining its function as to relate the waterfront and the urban river. This was observable at zone $4 \mathrm{a}, 6 \mathrm{~b}$ and 7 which had the provision of restaurant in the areas. But due to its positioned which backed the river, there was no activity generated that may relate the waterfront and the urban river. As the case of $1 \mathrm{a}, 3 \mathrm{c}$ though there was the existence of restaurants in the area, the accessibility and no continuity of activities to the restaurant were other suggested factors that became an obstacle for people to reach the place. Therefore it lessened the concentration of people in the area and reduced the efficiency of the place to be an element to integrate the waterfront with the urban river. This was also the same with the hotels. Hotels in some waterfront city took the advantage of the location to combine activities with the water but it was not the same case with the hotels in Kuala Lumpur waterfront. The hotels were only visually connected (in Zone 1a) or backed the river (in Zone 3a).

As for the green pocket spaces at Kuala Lumpur waterfront, it was suggested that without any building use nearby to the green pocket spaces to generate activity, not many people would come to the area and created a potential ambushed area (Manley and Guise, 1998). Based on the observation, it was suggested that most of the user stayed away from green areas which were isolated from the main pedestrian route (Zone $1 \mathrm{~b}, 3 \mathrm{c}$ ). Though it may offer a nice break in the city and may give the opportunity for the contextual integration between the waterfront and the urban river to happen, it was currently dominated by undesirable people (Whyte, 1980). 


\subsection{Water-independent building use}

Based on the observation, though there were water-independent building use which could function without the existence of water and give a low level of integration between the waterfront and the urban river, some of these building use may indirectly contribute to the integration in the context of $\mathrm{KL}$ waterfront. Examples of these were the public transportation point, shops/ commercial nodes and mosques which had the strength to pull the concentration of people due to its necessity in daily life.

Though public transportation and shops were highlighted by many literatures on its importance to bring people to waterfront, it contributed more to the necessity/dynamic activity rather than to integrate the waterfront to the urban river in the context of Kuala Lumpur. Static activities that may allow people to stay longer in an area with the opportunity to be integrated with the urban river would only be generated in the nearby water independent building use which had provision of ample space and seating for people to sit or socialise (Whyte, 1980). In addition to that, the integration was suggested to be able to happen if the positioning of these open spaces or seating was facing the urban river (Carr, 1992). This situation could be seen evident in the right bank of Zone 1a and the right bank of Zone $4 \mathrm{~b}$. In contrast to Zone $4 \mathrm{~b}$, though there was an ample space of plaza provided below the Light-Rail Transit (LRT) station and the plaza around it next to the river which invited people to the area, none of the facilities such as seating or terrace provided encourage the integration between the public and the urban river to happen. Though there were leisure activities available in the area none of it was observed to be integrated with the river.

This situation was also observable in the left bank of zone 6a, though the concentration of people were in the area that was enhanced by the existence of public transportation point, the pulling activity was very much due to the shopping area along Jalan Melayu and Jalan Masjid India. Based from the observation, one of the factors contributed to the non-integration between the people in the area and the urban river was due to the non-provision of space or seating in the area that faced the river. This was also the case with residential (Zone 1band 3a), offices (Zone $\mathrm{lb}$ and $4 \mathrm{a}$ ) and schools (Zone $3 \mathrm{~b}$ and $6 \mathrm{~b}$ ), clinic and workshops (Zone $1 \mathrm{~b}$ ) which needed some open space, seating, continuity of activities and building positioned that relate to the urban river to allow for the integration to happen. As for the mosque (Zone 4a), the occasional concentration of people which was accordance to the prayer time, may contribute to the static activity but its position in allowing visual accessibility to the river was important to allow the contextual integration between the waterfront and the urban river to occur. Otherwise, these building uses would only be concentrated within the boundary of the buildings.

\subsection{Conclusion}

The findings from this research, which aimed to evaluate the vital functional dimensions (diversity of use and continuity of activities) corresponded well with the literature. They also 
suggested that diversity of use and continuity of activities were essential in the context of Kuala Lumpur waterfront. However, there were other important and relevant factors identified such as the positioning and location, accessibility and the provision of space and facilities which might generate the static activities and allow people to stay longer to enjoy the urban river directly or indirectly. Without these, the waterfront would not be able to generate activities. The absence of the water-dependent building use might be related to other physical dimensions that should be considered. The physical dimensions which were vital to create a more holistic contextual integration between the waterfront and urban river were not exhaustive in this study due to the limitations of space. Finally, further research on this matter is highly recommended.

\section{Acknowledgement}

We would like to acknowledge the support from International Islamic University Malaysia for the financial assistance in the setting up of the research project.

\section{References}

Balsas, C.J.L. (2007). City Centre Revitalisation in Portugal: A Study of Lisbon and Porto. Urban Design, 12(2): p. 231259.

Browser, S. (1996). Good Neighbourhoods, a Study of In-town and Suburban Residential Environments, Westport, CT: Praeger.

Carmona, M., et al. (2003). Public Places Urban Spaces. The Dimensions of Urban Design, Oxford: Architectural Press. 312.

Carr, S., ct al., (1992).Public Space, Cambridge University Press, USA. Department of Irrigation and Drainage (2003). Guideline on Facing the River Concep.t

Friedmann, A., Ziming, C. and Zube, E., (1978). Environmental Design Evaluation, Plenum.

Corporation, New York. Gchl, J. (1971).Life Between Buildings. Using Public Space, The Danish Architectural Press.

Hoyle, B. S. (1994) A Rediscovered Resource: Comparative Canadian Perceptions of Waterfront Redevelopment in Journal of Transport Geography, 2, 19-29.

Hoyle, B.S (2001).Waterfront Revitalisation in an East African Port-City. Cities, 18(5): 297-313.

Jacobs, J. (1961). The Death and Life of Great American Cities., New York: Vintage.

Kotval, Z. and Mullin, J.R. (2001). Waterfront Planning as a Strategic Incentive to Downtown Enhancement and Livability, in Downtown. Revitalising the Centres of Small Urban Communities, A.M. Burayidi, Editor, Routledge. 312.

Lynch, L., M. Spence, and W. Pearson. (1976). Parameters/or the River, Sydney: National Trust of Australia. 
Manley, S. and R. Guise, Conservation in Built Environment, in Introduction to Urban Design, C. Greed and M. Roberts, Editors. 1998, Addison Wesley Longman Limited: England. p. 64-86.

Mann, R.B. (1988). Ten Trends in the Continuing Renaissance of Urban Waterfronts. Landscape and Urban Planning, 16: 177-199.

May, R., (2006). "Connectivity" in Urban Rivers: Conflict and Convergence between Ecology and Design. Technology in Society, 28: p. 477-488.

McCluskey. (1992). Roadform and Townscape, Oxford: Butterworth Architecture.

Owen, J., The Water's Edge: The Space Between Buildings and Water, in Urban Waterside Regeneration. Problems and Prospects, White K.N, et al., Editors. 1993, Ellis Horwood Limited: England.

Petrillo, J.E. (1985) The Urban Edge. Where the City Meets the Sea, in The Urban Edge. Where the City Meets the Sea, J.E. Petrillo and P. Grenell, (Ed). The California State Coastal Conservancy and William Kaufmann.Inc: USA.

Samant, S. (2004). Manifestation of the Urban Public Realm at the Water Edges in India - A Case Study of the Ghats in Ujjain. Cities. 21(3): p. 233-253.

Sanoff, H. (1991 ). Visual Research Methods in Design., New York: Van Nostrand Reinhold.

Schumacher, T. (1986).Buildings and Streets, in On Streets, MIT Press: Cambridge, Mass. 132-149.

Sternberg, E. (2000).An Integrative Theory of Urban Design. Journal of American Planning Association. 66(3): p. 265278.

Tibbalds, F. (2007).Places Matter Most, in Urhan Reader, M. Carmona and S. Ticsdcll, Editors, Architectural Press.

Trancik, R. (1986), Finding Lost Space. New York: Van Nostrand Reinhold Company.

Tunbridge, J. (1988). Policy Convergence on the Waterfront'? A Comparative Assessment of North American Revitalisation Strategies, in Revitalising the Waterfront: International Domension o] Dockland Redevelopment, B. Hoyle, P. D.A, and H. M.A, (Ed), John Wiley \& Sons Inc: Great Britain.

Ujang, N. (2007) Place Attachment and Users Perception of Kuala Lumpur City Centre, in Rekabentuk dan Senibina, University Putra Malaysia: Kuala Lumpur. p. 485.

West, N. (1989) Urban Waterfront Developments: A Geographic Problem in Search of a Model. Geoiorum, 20(4): p. 459-468.

Wood, ED., Renewing Urban Waterfront. Land Economics, 1965.41(2): p. 141-149.

Whyte, W.H. (1980). The Social Life of Small Urban Spaces., Washington: The Conservation Foundation.

Wren, M. D., Casazza, A. J. and Smart, J. E., (1983). Urban Waterfront Development, The Urban Land Institute, Washington. 